\title{
La Trêve y la pesadilla de la alteridad
}

La Trêve and the Nightmare of Alterity

\author{
Camilo Retana
}

DOI 10.15517/es.v81i2.49476 


\title{
La Trêve y la pesadilla de la alteridad La Trêve and the Nightmare of Alterity
}

\author{
Camilo Retana ${ }^{1}$ \\ Universidad de Costa Rica \\ San José, Costa Rica
}

Recibido: 14 de diciembre de $2020 \quad$ Aprobado: 22 de abril de 2021

\begin{abstract}
Resumen
En este artículo presento una propuesta interpretativa de la primera temporada de la serie belga La Trêve (2016), según la cual lo que dicha ficción escenifica es el problema de la percepción cultural de la alteridad en sus distintas versiones (racial, étnica, de clase, entre otras) así como la posible violencia ligada a ella. A partir de esa hipótesis de lectura, propongo entender el desenlace de La Trêve en términos de una apuesta narrativa con alcances políticos en la que, en lugar de resolverse la pregunta clásica del policial a propósito de la autoría del crimen en términos individuales (y por ende psicologizantes), se opta por subrayar la responsabilidad del colectivo en la protección/pérdida de toda vida, así como la actual necesidad política de trabajar porque podamos lamentar las pérdidas, incluso, de aquellos considerados distintos.
\end{abstract}

Palabras clave: programa de televisión; racismo; migración; exclusión social; violencia

\begin{abstract}
In this article, I present an interpretive proposal of the first season of the Belgian TV series La Trêve (2016), that suggests that said fiction portrays the issue of cultural perception of alterity in its different versions (racial, ethnic, class, etc.) and the possible violence attached to it. Drawing from this hypothesis, I propose to understand La Trêve's denouement in terms of

${ }^{1}$ Doctor en Filosofía, Universidad Nacional de la Plata. Profesor Catedrático en la Escuela de Filosofía de la Universidad de Costa Rica y Director del Posgrado en Artes de la Universidad de Costa Rica. ORCID: 0000-0002-6442-7092. Correo electrónico: camiloretana@gmail.com
\end{abstract}


a narrative stand with political reaches that instead of answering the classic police question by the way of individual, and thus psychologizing, crime authorship terms, highlights the collective responsibility in the protection and loss of every life, as well as the current political need for work so we can mourn the losses, even of those who are considered different.

Keywords: TV show; racism; migration; social exclusion; violences 


\section{El contexto}

Inscritas dentro de la larga tradición de la literatura policial, las teleseries de detectives reubican los viejos motivos del crimen, la búsqueda de la verdad, la crudeza de la vida urbana y la violencia sobre el cuerpo en el contexto de las sociedades digitales hiperconectadas de finales del siglo XX e inicios del siglo XXI. Este ejercicio de recontextualización del género policíaco supone no solo una labor de actualización de los tropos mencionados, sino también la puesta en marcha de una serie de operaciones narrativas particulares, dada la temporalidad más dilatada propia del mundo de las teleseries. La labor de interpretación de este tipo de productos audiovisuales -una labor si se quiere aún en ciernes- se plantea entonces como un trabajo de desciframiento de nuestro presente (Cortés \& Retana, 2021, pp. ix-xv). A saber, en el análisis de las series está en juego la pregunta de cómo narramos nuestro mundo y de lo que, en consecuencia, queremos que ese mundo sea.

En este marco, presento una propuesta interpretativa de la primera temporada de la serie belga La Trêve (2016), según la cual lo que dicha ficción escenifica es el asunto de la percepción cultural de la alteridad en sus distintas versiones (racial, étnica, de clase, entre otras). La alteridad, como se sabe, es un problema con abolengo dentro de la filosofía. Desde las formulaciones del idealismo alemán -en las que la dialéctica entre el yo y el otro se encuentra en el centro de una serie de problemas históricos, psicológicos y morales- hasta las reflexiones fenomenológicas y existencialistas -en las que la conflictividad y la interdependencia del sí mismo y el otro adquieren carices ontológicos- la pregunta por el modo en que concebimos al prójimo ocupa un lugar central en la historia del pensamiento. Al hilo de esta tradición, la alteridad se presenta en distintos audiovisuales contemporáneos, no únicamente como un problema ontológico, sino también como un fenómeno vinculado al modo en que las diferencias culturales (de clase, género o raza, por ejemplo) se utilizan como base para construir imaginarios en los cuales se clasifica a los individuos, e incluso se les jerarquiza. La Trêve es uno de esos audiovisuales. En consecuencia, mi interés es leer esta teleserie como un documento de época que recoge una gama de preocupaciones políticas ligadas a algunos de los fenómenos de desigualdad más acuciantes de este tiempo.

\section{La trama}

La ficción belga La Trêve (2016) presenta un escenario típico policial. Un atormentado detective regresa con su hija, tras enviudar, al pueblo en el que pasó una parte de su 
infancia. A pesar del verde y de las amplias arboledas, del campo abierto y el aire bucólico, una atmósfera de asfixia y claustrofobia parece reinar en la aldea. La afabilidad y candidez de los pobladores rápidamente se torna indiferencia y abulia: frente al cuerpo mutilado de un joven negro, ningún policía, incluido el jefe del departamento, parece interesado en indagar las causas. Tampoco los lugareños -sumidos de por sí en otros menesteres: la construcción de una polémica represa, el recién celebrado carnaval- parecen conmovidos o indignados: todo mundo se muestra anuente a consentir que se trata de un suicidio, toda vez que el cadáver aparece flotando río abajo. Nadie se muestra dispuesto a reparar en que una vida se ha perdido, excepto, claro está, el protagonista de la serie: el detective Yoann Peeters.

Al hilo de esta descripción, la teleserie del joven director belga Matthieu Donck, producida por la Radio-télévision belge de la Communauté Française (RTBF) y difundida mundialmente a través de Netflix, se presenta tan solo como otra convencional trama policíaca, aunque, cabe añadir, con un buen manejo del suspenso, una lograda estética fotográfica y un más que buen nivel actoral ${ }^{2}$. No obstante, conforme la narración avanza, los motivos antes descritos (el cadáver a la deriva, el detective atormentado, la intriga en torno a los sospechosos) comienzan a ganar complejidad a través del perfilamiento sociológico de sus personajes. En este sentido, La Trêve se inscribe en una tendencia de las teleseries actuales a politizar sus tramas (piénsese, por mencionar tan solo algunos ejemplos de ficciones que figuran o alguna vez figuraron en la propia plataforma Netflix, en trabajos como The Killing (2011), Top of the Lake (2013), Happy Valley (2014) o The Sinner (2017), en las que la vulnerabilidad de las víctimas obedece a su posición social, ya sea por su edad, su género, su sexualidad o su condición socioeconómica). Así, mientras Román Setton (2011) plantea la hipótesis de que existe una progresiva despotenciación crítica de la literatura policial -de modo tal que cuanto más masivos, los policíacos tienden a tornarse menos críticos-a nivel audiovisual la tendencia pareciera ir en sentido contrario ${ }^{3}$.

\footnotetext{
2 A propósito de la evolución y los avatares del policial, desde su aparición en el campo literario hasta su exportación al ámbito de las teleseries, se puede consultar el completo artículo de Giancarlo Cappello De paseo por el crimen: género y trayecto del policial en la pantalla chica (2011). El exhaustivo recorrido del autor tiene, no obstante, la limitación de no considerar el vector político como eje de historización del género policíaco, el cual, como veremos, se torna cada vez más importante en la actualidad.

3 Para Sophie Fuggle (2010), el punto clave en este cambio de dirección habría que buscarlo en la celebérrima teleserie de HBO The Wire (2002), creada por David Simon
} 
En el caso de La Trêve, esta vocación politizante se da a través de la asignación de atributos caracterológicos a la víctima del asesinato que motiva la trama. Driss Assani (interpretado por Jérémy Zagba) es un inmigrante de Togo que viaja a Bélgica en busca de la variante europea del sueño americano. Contratado por un pequeño equipo de fútbol de la localidad, Assani fantasea con convertirse en un sobresaliente futbolista, a la manera del marfileño Didier Drogba. Su motivación, no obstante, no es únicamente conquistar la fama, pues del otro lado del Mediterráneo su familia atraviesa serias limitaciones económicas. Empero, como en tantas otras historias de la vida real, el arribo de Assani a Heiderfeld, la pequeña villa en la cual se desarrolla la historia, está muy lejos del idilio. Además de la barrera del idioma, Assani se encuentra con un campeonato de fútbol amañado por las mafias, una interacción regida por secretismos, una clase política corrupta y una sociabilidad decididamente hostil en la que cada quien intenta sacar provecho del otro.

Como Assani, el detective Yoann Peeters ocupa una ambigua posición respecto de la comunidad. Ambos pertenecen a ella, pero conservan, no obstante, el estatuto de forasteros. Esta peculiar forma del estigma les proporciona un punto de vista singular que las personas de la villa no pueden compartir en la medida de su condición de autóctonos. De un modo que recuerda la opinión de Erving Goffman según la cual "la mayoría de los estigmatizados tiene acceso a una versión intelectualmente elaborada de sus puntos de vista" (Goffman, 2010, p. 41), tanto Peeters como Assani parecen ver lo que otros no y desconfiar de lo que el resto considera natural. Assani, por un lado, pone en evidencia, con su sola presencia, el contrato social implícito que rige en la comunidad: hace emerger el pasado filonazi de su casero; muestra, por contraste, el trato erótico violento de los hombres del pueblo, y saca a flote, sin quererlo, la corrupción de la política y las instituciones deportivas. Peeters, por su parte, cuestiona a través de sus métodos de investigación la inoperancia policial; a través de su sed de verdad, los pactos de silencio, y a través de su falta de familiaridad con el resto de pobladores y su consecuente sospecha indiscriminada de cada uno de ellos, el lazo social que los ata ${ }^{4}$. Mientras la alteridad de Peeters se traduce tan solo en un ojo

4 Se trata de un rasgo que muchas ficciones audiovisuales importan de la literatura policial. Como lo señala Setton, "dentro de [un] marco de incomunicación en que cada uno es un extranjero para su prójimo, solamente el detective es capaz de ver las relaciones y conexiones reales y verdaderas, que se esconden bajo la superficie opaca que la novela policial propone para ser descifrada" (2011, p. 196). 
aguzado a la hora de investigar y, a lo sumo, suscita la queja por parte de sus compañeros debido a sus heterodoxos métodos policiales, la alteridad de Assani no solo lo conduce a la muerte, sino que se presenta frente a la comunidad como la materialización de un mal sueño: la pesadilla de la alteridad.

\section{Las caras de la diferencia}

En el centro de las peripecias experimentadas por el personaje interpretado por Jérémy Zagba, tras su arribo a Heiderfeld, se encuentra el racismo. La teleserie belga es cuidadosa a la hora de desplegar su crítica hacia esta forma de discriminación y evita la denuncia fácil y panfletaria. La Trêve no se interesa tanto por retratar la psique del racista, sino por acometer una radiografía más amplia del racismo en tanto fenómeno social. Así, antes que fijar cómodamente el racismo en un solo personaje, la serie opta por retratar la forma en que el ejercicio de la violencia y la exclusión racial se distribuye a lo largo de todo el tejido social5. La opción por este enfoque político -en lugar de psicológico- del problema racial resulta apropiado en un contexto en el cual, frente al declive histórico de las fundamentaciones científicas (o en realidad pseudocientíficas) y más específicamente biológicas (o pseudobiológicas) del racismo, este pasa a ser un fenómeno cuyo fundamento se revela estrictamente imaginario. David Le Breton señala en este respecto cómo

el racismo se basa en una relación fantasmática con el cuerpo. Se arraiga en el interior de los basamentos pasionales que alimentan la vida colectiva, nutren sus proyectos, sus movilizaciones y motivan sus tolerancias y violencias... La afectividad reprimida, las frustraciones, las resignaciones son drenadas por estas formas vacantes que ofrecen una superficie de proyección a todos los matices posibles del resentimiento. El racismo procede de una fantasmática del cuerpo (2011, pp. 75-76).

El cuerpo como superficie de proyección, el racismo como fantasmática: en La Trêve estas premisas se condensan en el cuerpo de Driss Assani. De él solo tenemos noticia a

5 Se trata, de nuevo, de un giro que aparece con The Wire (2002), la serie de HBO. Como lo señala Fuggle, "uno de los problemas fundamentales de la crítica al racismo... es que tiende a culpar a ciertos individuos más que a analizar las estructuras de poder que de partida permiten que existan y proliferen los discursos racistas... The Wire demuestra con precisión cómo el color funciona como un discurso que apenas hace referencia a cualquier verdad inherente sobre la identidad individual" (p. 154).

ESCENA. Revista de las artes, 2022, Vol. 81, Núm. 2 (enero-junio), pp. 5-17 
través de la memoria y las narraciones de los pueblerinos. A saber: Assani es el resultado de un conjunto de representaciones, habida cuenta de que su aparición en el primer capítulo se da ya bajo la forma de un cadáver. Pero hay algo del muerto que se rebela contra la calma narrativa con la cual lo describe la comunidad que lo sobrevive. Entonces, Assani se presenta en los sueños de los pobladores a la manera de un fantasma que porta los signos del recuerdo mutilado. Consecuentemente, su cuerpo en esas pesadillas lleva consigo las marcas de la violencia: a menudo luce zaherido, lastimado; otras veces de él emana sangre. Se trata del viejo tropo freudiano del "retorno de lo reprimido" (Freud, 1991, p. 163): la representación que aparece allí donde el mecanismo psíquico de la defensa no logra el cometido de bloquear aquello que atenta contra el yo, en este caso social. El fantasma de Assani aparece en las pesadillas a la manera de una alteridad perturbadora y acechante, representación incompatible con el modo en que la comunidad se imagina a sí misma.

Además de la diferencia racial, Assani encarna también al otro africano empobrecido, de modo que el eje de clase se coloca de un modo sutil en el centro de la trama. En consecuencia, el dinero opera en La Trêve a la manera de un personaje. No solo porque Assani arriba a Heiderfeld con la motivación de ayudar a su necesitada familia, sino porque en la teleserie el dinero funciona como elemento organizador de la sociabilidad y los afectos. El dinero (no la economía, ni la riqueza, sino el efectivo constante y sonante) aparece en varias escenas como un recurso narrativo que moviliza actos, que mediatiza vínculos (las más de las veces codiciosos e interesados) y que sostiene jerarquías. El dinero motiva las mafias del futbol que amañan los partidos del equipo en el que juega Assani; es el fin que justifica la construcción de una enorme represa a todas luces incompatible con el frondoso paisaje lugareño; es, también, el elemento que permite la organización de licenciosas fiestas sexuales que algunos pueblerinos celebran con sigilo al filo de la noche. Una constante, sin embargo, se mantiene: los blancos son los que circulan el dinero; Assani tan solo un negro que lo pretende y que, para hacerse con él, debe ir en contra de sus propios valores.

Assani es también, por último, la encarnación de la alteridad sexual. La Trêve es, por lo tanto, a la vez, un sutil retrato de una otredad sexualizada. Las mujeres de Heiderfeld desean a Assani, pero siempre a la manera de un sustituto de sus propios hombres. En concreto, Zoé Fischer (interpretada por Sophie Maréchal) e Inès Buisson (interpretada por Anne Coesens) anhelan en Assani al hombre blanco que no pudieron tener. Zoé, atrapada en una relación de violencia con su pareja, e Inès, adolorida por un aborto y un desamor de juventud con el propio detective Yoann Peeters, ven en Assani la oportunidad de resarcir sus 
amores fallidos. Sin embargo, a la larga, ninguna de las dos repara en él como un sujeto: la una lo abandona mientras la otra juega un rol fundamental en su asesinato. El cuerpo de Assani es erotizado del mismo modo en el que la imaginería de la conquista rodeaba el cuerpo colonial del indio americano de un aura sexual; en ambos casos el deseo es resultado de una diferencia exotizada 6 .

La Trêve encarna en Assani, así, las múltiples caras de la alteridad: racial, económica y sexual. Su asesinato condensa el deseo inconsciente de la comunidad de acabar con ese extranjero molesto que impide los goces de la mismidad. Su cadáver, sin embargo, encarna esa incómoda extrañeza que irrumpe para perturbar la calma normalidad.

\section{El desenlace}

Vista así, la primera temporada de la teleserie La Trêve (2016) constituye una puesta en escena de las distintas formas actuales que reviste la exclusión racial: la pobreza, la migración forzada y la violencia física. Siguiendo esta propuesta interpretativa, quisiera proponer una lectura del final de la temporada de la serie acá analizada en la que se enfatiza la dimensión política que recorre toda la trama. En otras palabras, deseo proponer la hipótesis de que, en lugar de apelar al clásico final catártico de la narrativa policial, centrado unilateralmente en develar tanto el asesino como sus motivos (dicho sea de paso, con una fuerte carga psicologizante, en la medida en que, las más de las veces, los crímenes se encuentran explicados por desórdenes de la personalidad, perturbaciones psíquicas o anomalías de la afectividad mal gestionadas), La Trêve opta por un desenlace con carácter político. Así, desplaza la clásica pregunta por la autoría del crimen y coloca, en su lugar, la pregunta filosófica acerca de la responsabilidad social en la protección o en su defecto el abandono de la vida.

El asunto de la responsabilidad ocupa todo un capítulo dentro de la historia de la ética y el derecho que no es posible recorrer acá. Para nuestros efectos, sin embargo, resulta relevante el modo en que esta historia transita de una concepción acaso más voluntarista, centrada en un sujeto con una agencia nunca sometida a revisión, hacia una noción con-

6 Sobre el carácter mistificante con que la imaginería colonial representaba al indio americano, dotándolo de una carga erótica, véase Jáuregui (2000, p. 21). Setton remarca, por otra parte, el modo en que el cuerpo, en el policial, se convierte en una entidad rodeada de un aura etérea de indescifrabilidad (2011, p. 206) -en el caso La Trêve, cabe especular, se trata de un aura erotizada. 
temporánea con un cariz más sociocultural y con ello más político. Dicho de otro modo, la responsabilidad, al menos si nos atenemos a autores contemporáneos como Adorno, Levinas o Laplanche, no designa un epifenómeno de la voluntad, sino una disposición relacional. Judith Butler señala en esta línea cómo la responsabilidad no se da en dominios en los cuales los sujetos ya están plenamente constituidos, sino que, al contrario, tiene lugar allí donde las relaciones sociales permiten la co-constitución de dichos sujetos. Para Butler, "en rigor de verdad, la responsabilidad no pasa por el cultivo de una voluntad, sino por la utilización de una susceptibilidad no querida como recurso para dar respuesta el otro" (Butler, 2009, p. 127). En breve: la responsabilidad no solo se juega en una relación que el yo establece con el otro, sino que constituye un fenómeno que posibilita la propia construcción del yo y del otro. No somos sujetos responsables de relacionarnos de un modo u otro con la alteridad, sino que la responsabilidad es eso que permite tanto mi existencia como la de esa alteridad. Estamos, desde un comienzo, como lo sabían ya los viejos existencialistas, habitados por los otros.

En La Trêve, esta dimensión propiamente colectiva de la responsabilidad recorre toda la trama. Más aún, la serie puede entenderse como un relato que, a través de la ambigüedad de varios de sus personajes, pone en evidencia el papel clave que opera el colectivo en la preservación o el desamparo de una vida. A lo largo de los diez episodios que componen la primera temporada de la serie, los guionistas acometen varias fintas para confundir en este respecto a las personas espectadoras. Buena parte del gancho narrativo de la serie depende de lo bien conseguidos que están cada uno de esos giros efectuados para engañar al espectador. Dicho en breve, la narrativa de la serie funciona en la medida en que cada uno de los personajes relevantes se presenta en algún momento de la serie como un sospechoso verosímil, con lo cual queda abierta la pregunta de si, en vida, Assani habrá recibido de cada uno de ellos solidaridad o violencia. Este recurso, por lo demás empleado en varias teleseries policiales de las últimas décadas, consigue en La Trêve un tipo de densificación particular efectuada a partir de la repetición. A fuerza de tornar a todos y cada uno de los pobladores de Heiderfeld un potencial asesino, los guionistas dejan en el aire la pregunta acerca de una potencial responsabilidad colectiva en el deceso de Assani. En este sentido, la actitud desconfiada del detective Yoann Peeters resulta fundamental, ya que a lo largo de su investigación nunca da por descontada la inocencia de los sospechosos (para el desasosiego de sus colegas, que a menudo resienten las especulaciones del detective, pues se niegan a creer que sus vecinos de todos los días puedan acometer actos de crueldad). En el imaginario narcisista de Heiderfeld nadie pudo cometer el crimen; en el del 
detective Peeters, en cambio, cualquiera pudo haberlo cometido. Los propios espectadores basculamos entre una y otra posibilidad, hasta que por efecto de la repetición y la densificación por ella generada, nos vemos obligados a convenir con la hipótesis del detective.

¿Qué significa, pues, que cualquiera podría haber cometido el crimen? ¿Qué tipo de sociabilidad se funda sobre la base de una subjetividad como esta, marcada por la desconfianza y la violencia mutuas? El propio nacimiento del género policial se encuentra ligado a preguntas como estas. La literatura policial nace, en efecto, de la mano del anonimato posibilitado por las grandes urbes y de un cambio de escala que afecta la sociabilidad básica. Mientras el mundo preindustrial planteaba una lógica relacional más cercana e íntima entre los pobladores, las sociedades capitalistas instalan un lazo social marcado por el anonimato, la indiferencia y la desconfianza hacia los otros. Así, en La Trêve, esa mirada de sospecha con marcado acento hobbessiano, en la que todos los personajes son sospechosos hasta que se demuestre lo contrario, marca el desenlace de la historia. Si bien los guionistas, tal y como se estila dentro del género policial, develan quién cometió el crimen y revelan un presunto motivo, lo esencial del final se encuentra en otra parte: para el momento de ese develamiento catártico resulta comprensible para los espectadores que a Assani lo mata todo el pueblo. Dicho de otro modo, el desenlace muestra una responsabilidad compartida en un asesinato finalmente acometido en diferentes etapas y niveles. Es decir que Assani muere por efecto de la violencia social con la que lidia desde su llegada a Bélgica. Es como si quien comete el asesinato se limitara a dar la última estocada a un cuerpo que ya había sido abandonado por la comunidad entera.

Así, el final nos devuelve al punto de partida de la serie. Todo ocurre como si nadie hubiera querido dar con la explicación del crimen, en la medida en la que todos, hasta cierto punto, habían sido, ya sea por acción u omisión, partícipes del mismo. Esto recuerda a la interrogante planteada en otros contextos (por ejemplo, en el caso de Auschwitz o de las desapariciones forzadas cometidas en contextos dictatoriales en distintos momentos de la historia de América Latina) acerca de la posibilidad de establecer responsabilidades colectivas en la comisión de un crimen. Pero más allá de entrar en esos debates históricos, La Trêve pareciera constituir un recordatorio de hasta qué punto es necesario no solo reconocer la alteridad, sino también poder lamentar su pérdida.

En este sentido, el que la vida de Assani no fuera objeto de protección ni de acogida, se corresponde con el hecho de que, una vez asesinado, la comunidad tampoco llorará su muerte. Si como lo señala Judith Butler, "la distribución diferencial del duelo público es 
una cuestión política de enorme importancia" (2010, p. 64), la indiferencia pública ante la muerte de Assani, en la serie La Trêve, no solo constituiría un índice de la violencia que el personaje padece en vida, sino también un signo de la necesidad política, presente en nuestras sociedades, de una ética que permita lamentar la muerte, incluso, de aquellos a quienes consideramos extraños. 


\section{Referencias}

Butler, J. (2009). Dar cuenta de sí mismo. Violencia ética y responsabilidad. Buenos Aires: Amorrortu.

Butler, J. (2010). Marcos de guerra. Las vidas lloradas. Barcelona: Paidós.

Cappello, G. (2011). De paseo por el crimen Género y trayecto del policial en la pantalla chica. Contratexto, 19, 147-161.

Cortés, M. \& Retana, C. (2021). Locos por las series. San José: Editorial de la Universidad de Costa Rica.

Freud, S. (1991). Nuevas puntualizaciones sobre la psiconeurosis de defensa. En S. Freud, Obras completas (vol. 3), (pp. 157-184). Buenos Aires: Amorrortu.

Fuggle, S. (2010). Cortocircuitando el juego del poder. The Wire como crítica de las instituciones. En D. Simons, (ed.) The Wire. 10 dosis de la mejor serie de la televisión. (pp. 143-161). Madrid: Errata Naturae.

Goffman, E. (2010). Estigma. La identidad deteriorada. Buenos Aires: Amorrortu.

Jáuregui, C. (2000). Saturno caníbal: fronteras, reflejos y paradojas en la narrativa sobre el antropófago. Revista de Crítica literaria Latinoamericana, (51), 9-39.

Le Breton, D. (2011). La sociología del cuerpo. Buenos Aires: Nueva Visión.

Setton, R. (2011). Pensar la literatura policial: Siegfried Kracauer, Walter Benjamin, Ernst Bloch, el género y la disolución de los vínculos comunitarios. Constelaciones: Revista de Teoría Crítica, (3), 193-207. 